\title{
Estimating Timber Stock of Ehime Prefecture, Japan using Airborne Laser Profiling
}

\author{
Hayato Tsuzuki ${ }^{* 1}$, Ross Nelson ${ }^{* 2}$ and Tatsuo Sweda*1
}

\begin{abstract}
The timber stock of mainland Ehime prefecture was estimated using airborne laser profiling data. Our provisional analysis revealed that: 1) at $5,435 \mathrm{~km}^{2}$, the laser estimate of land area obtained as a simple product of flight path length and its $4 \mathrm{~km}$ width was fairly consistent with the figure of $5,455 \mathrm{~km}^{2}$ by the Geographical Survey Institute, considered the most reliable of the government statistics; 2) on the other hand, at $176 \mathrm{million}^{3}$ for the entire prefecture our estimate of standing timber stock turned out to be twice as much as the government figure of 87 million $\mathrm{m}^{3}$; 3) judging from the precision in land-area estimation and results from other research, our estimate is considered more likely to represent the actual timber stock than the government figure; 4) thus airborne laser altimetry would provide more accurate national forest carbon budget for the Kyoto Protocol than does the existing national forest inventory; 5) at the present density of laser profiling transects, $4 \mathrm{~km}$ apart from each other, however, no reasonable accuracy is expected at the municipality level.
\end{abstract}

Keywords: timber stock, airborne laser profiling, prefecture-wide inventory, Ehime prefecture, Kyoto protocol

\section{INTRODUCTION}

Japan is now determined to base its forest carbon budget accounting of the Kyoto Protocol on the Forest Inventory Book (FIB), an original system of inventorying the nation's forest resources by sub-compartments as tiny as one-tenth of a hectare. However, the FIB is reputed for its inaccuracy due partly to its obsolescent bookkeeping system and partly to lack of field checks in recent decades, and without major reform it may not survive long beyond the first commitment period of the Protocol. This study was intended to develop a new system of national forest inventory using airborne laser altimetry with particular aims of: 1) developing a prefecturewide laser altimetry inventory system; 2) assessing prefectural forest carbon budgets using multi-temporal airborne laser profiling at 2-year intervals, and 3) comparing the resulting inventory and carbon sequestration estimates with the

Corresponding author: Hayato Tsuzuki

${ }^{* 1}$ Faculty of Agriculture, Ehime University

3-5-7 Tarumi, Matsuyama 790-8566 Japan

${ }^{* 2}$ Biospheric Sciences Branch, NASA-Goddard

Space Flight Center

Greenbelt, MD 20771 USA corresponding official figures of the government. In this paper the first outcome of the project, i.e. an estimate of prefectural forest inventory resulting from the term-head airborne laser profiling and its comparison with the existing government statistics are reported.

\section{MATERIALS AND METHODS}

Study Area and Laser Profiling

Ehime $\left(5,677.12 \mathrm{~km}^{2}\right)$ is one of the 47 prefectures of Japan, comprising of mainland $\left(5,455.38 \mathrm{~km}^{2}\right)$ and numerous small islands $\left(221.74 \mathrm{~km}^{2}\right)$ to the north and west in the Seto Inland Sea (Fig. 1). The terrain is rugged especially along the Ishizuchi (1,982 $\mathrm{m}$ a.s.1.) Range, which constitutes the border with Kochi prefecture to the south. According to the government statistics $71 \%$ of the prefecture or $3,870 \mathrm{~km}^{2}$ is forested, of which approximately $3 / 5$ is plantations primarily of Cryptomeria japonica and Chamaecyparis obtusa and the remaining $2 / 5$ is secondary natural forests of mainly broadleaved species (OCHI et al., 2006). Approximately 10\% of the forested land is nationally owned and managed directly by the Forestry Agency (ShiKoKu Regional Forest OfFice, 2006).

The term-head laser profiling mission with NASA's Portable Airborne Laser System (PALS, NELSON et al., 2003), mounted on-board a Bell 206 helicopter was flown September 


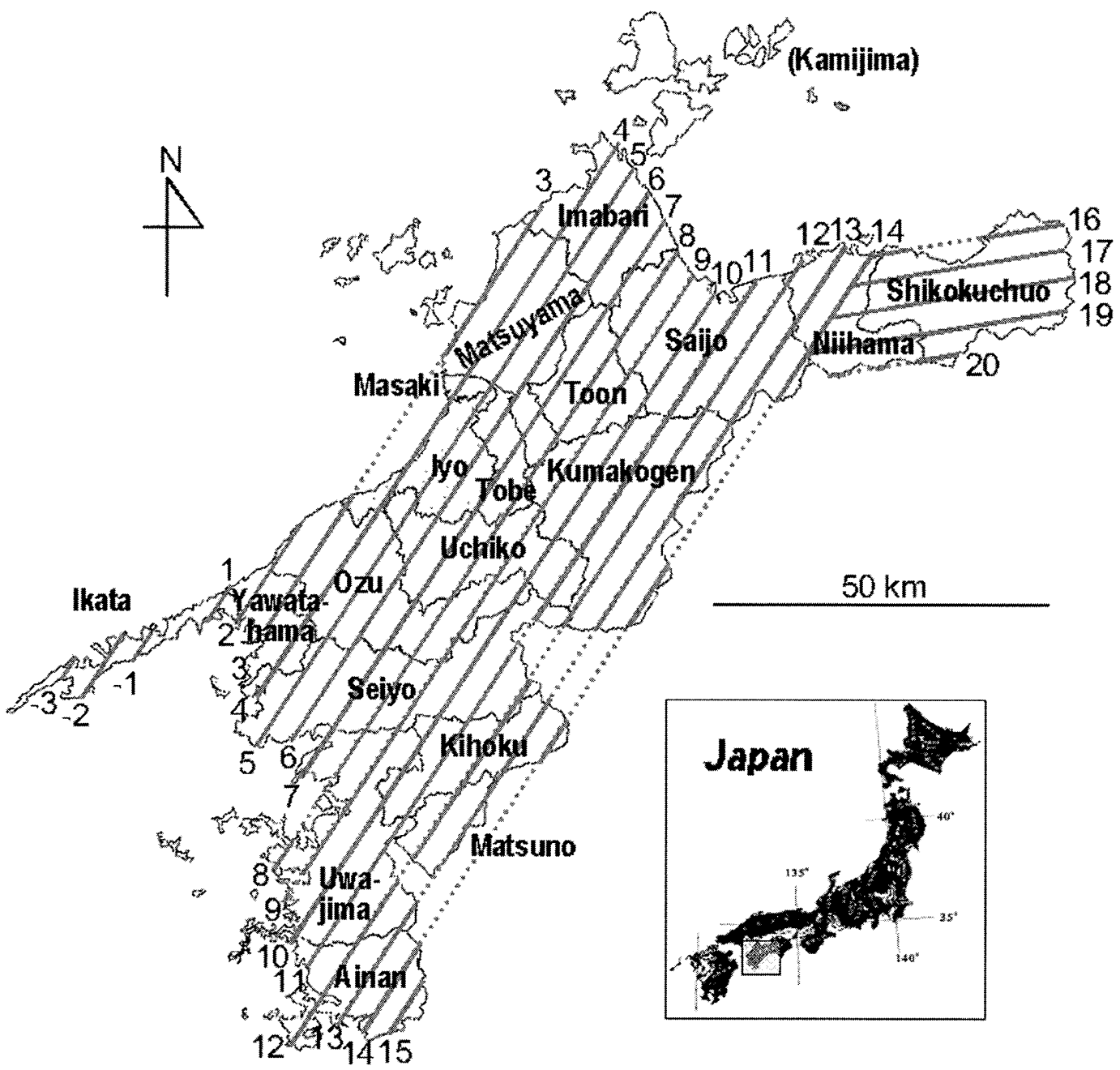

Fig. 1 Study area of Ehime prefecture and profiling transects

10-17, 2005 over the mainland Ehime in a series of 23 parallel flight lines four kilometer apart, totaling 1,358.7km (Fig. 1). The helicopter was flown $200 \mathrm{~m}$ above ground at a target ground speed of $180 \mathrm{~km} / \mathrm{hr}$ with an alternating first/last pulse altimetry data retrieval frequency of $400 \mathrm{~Hz}$. However, slow climb-ups and -downs over the steep terrain reduced the nominal data retrieval interval of $12.5 \mathrm{~cm}$ along the flight track to an overall average of $8.5 \mathrm{~cm}$ with a local minimum as short as $3 \mathrm{~cm}$.

\section{Land-area Estimation}

As a way of assessing the accuracy of timber stock estimation by laser profiling, laser-based land area was also estimated and compared with corresponding government figures from the Geographical Survey Institute (GSI, http://www.gsi.go.jp). The laser estimates were obtained as a simple product of flight length and width of $4 \mathrm{~km}$ between the flight lines. For a fair comparison, insular areas totaling $221.74 \mathrm{~km}^{2}$ were discounted in the government figures. Only the islands equal to or larger than $1 \mathrm{~km}^{2}$ are accounted for in the insular total, but the remaining error was deemed negligible.

Timber Stock Estimation

The standing timber stock was estimated on a basis of its correlation with the area of vegetation profile induced from airborne laser profiling data as a difference between canopy and topographic profiles (TsuzukI, 2004; Tsuzuki et al., 2006), i.e. according to a regression of standing timber stock $V$ $\left(\mathrm{m}^{3} / \mathrm{ha}\right)$ on cross sectional area $S\left(\mathrm{~m}^{2} / \mathrm{m}\right)$ of vegetation profile $f(x)$,

$V=a S=a \int f(x) d x$

The coefficient $a$ in the above equation was determined 


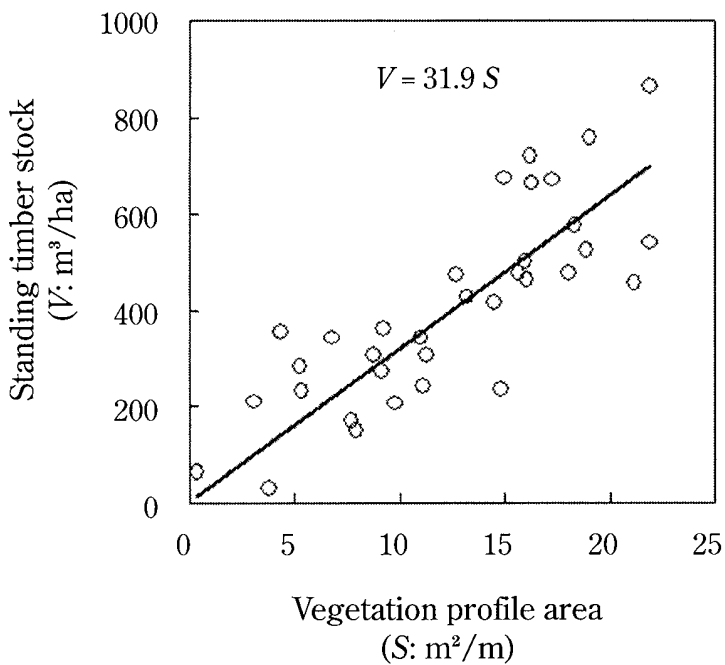

Fig. 2 Regression of standing timber stock on vegetation profile area

by the regression of actual standing timber stock measured on the ground on the vegetation profile area calculated from the laser altimetry data as shown in Fig. 2.

Timber stock measurement was made in sample plots established directly under the laser profiling flight path. A total of 34 sample plots were established, one each in 16 stands of Cryptomeria japonica, 12 of Chamaecyparis obtusa and six of mixed broadleaved species. The plot size varied from 21 to $829 \mathrm{~m}^{2}$ depending on the stand height but was made greater than the area of a square with its side length equal to stand height. In each plot stem diameter at breast height ( $\mathrm{dbh}$ ) was censused and then converted to stem volume by allometric volume equations made from a total of 219 sample trees consisting of 58 C. japonica, 79 C. obtusa, 23 Pinus densiflora and 59 broadleaved species, felled in and around the sample plots and measured for stem volume. Rather than differentiating by species, only two volume equations, i.e., one for conifer and the other for broadleaves were used since no significant difference was found among the coniferous species.

Eventually, the coefficient $a$ turned out to be 31.9 (dimensionless) as has been shown in Fig. 2. The validity of the coefficient was tested then by: 1) dividing the sample plots randomly into equal halves of 17 plots each, and 2) comparing the measured timber volume of the first half against its estimate made using coefficient $a$ determined from the other half. The process was repeated 10 times by random selection of plots. Note that the above coefficient is still a temporary figure since the plot measurement and data compilation are still under way for the ultimate total of 200 plots.

In this process of standing timber stock estimation, no prior delineation of forest area from other land use was conducted for two reasons. Firstly, with minutely fragmented land use over the past, delineation of forests from other land use is too complicated and tedious even for possible improvement in accuracy it may bring. Secondly, with the first and last returns registering the same clearance in the area devoid of vegetation, no vegetation profile is formed, and thus the other land use than forest do not virtually affect the timber estimate even if other land-use categories are included in the analysis. The only sources of possible over-estimation are small forested parks in and in the vicinity of city, shade trees along the road etc. for which $3 \%$ allowance was given in the final estimate. The timber stock estimation was tallied by municipality and compared with the corresponding government statistics.

The government estimates of timber stock used for comparison was the forest inventory book (FIB) compiled in basically the same method throughout Japan but with different yield tables specific to districts as well as to species and site quality. In Ehime prefecture, five forest districts of nearly the same area are distinguished by major watersheds. Species distinguished in each district are C. japonica, C. obtusa, Pinus spp., Quercus spp. and other broadleaves with five site quality classes for conifers and three for all the broadleaves. Based on a prefecture-wide yield survey made $40-50$ years ago, the yield tables were compiled to give standard annual volumetric increment by age class of five-year interval for each species and site class. With reference to these yield tables by a mainframe, standing timber volume is routinely calculated by adding corresponding increment year after year for each subcompartment consisting of trees of the same age and same species category. The sub-compartment timber volumes are added for the compartment totals, which then are added for municipal totals and subsequently for the prefecture total with the harvested sub-compartments reset to null according to the obligatory harvest reports from forest owners.

Widely reputed inaccuracy of the FIB is generally considered to have arisen from a multitude of causes. The most significant one of them would be complete lack of field checks in the last few decades due to declining forestry budgets and personnel to result in accumulated errors. Another could be the deviation in the yield tables made when the nation's forests were significantly younger with over representation of younger stands and under representation of mature stands.

\section{RESULTS AND DISCUSSIONS}

\section{Validity of the Laser Estimates}

The results of the validity test for the regression coefficient $a$ and estimated timber stock by randomly halving 34 sample plots into estimation and verification groups are given in Table 1. In each round of the test repeated 10 times, timber stock of the verification group was estimated by a regression established using data from the estimation group, and then checked against measured counterparts. First of all, 
Table 1 Validity tests for regression coefficient a of equation (1)

\begin{tabular}{|c|c|c|c|c|c|c|c|}
\hline \multirow{2}{*}{\multicolumn{2}{|c|}{ Repetition }} & \multirow{2}{*}{\multicolumn{2}{|c|}{$\begin{array}{l}\text { Correlation of vegetation } \\
\text { profile area with standing } \\
\text { timber stock }\end{array}$}} & \multirow{3}{*}{$\begin{array}{l}\text { Regression } \\
\text { coefficient }\end{array}$} & \multicolumn{2}{|c|}{$\begin{array}{c}\text { Meari timber stock } \\
\left(\mathrm{m}^{3} / \mathrm{ha}\right)\end{array}$} & \multirow{3}{*}{$\begin{array}{c}\text { Error } \\
\frac{V_{\text {est }}-V_{\text {at }}}{V_{\text {att }}} \\
(\%)\end{array}$} \\
\hline & & & & & \multirow{2}{*}{$\begin{array}{c}\text { Estimate } \\
\left(r_{s t}\right)\end{array}$} & \multirow{2}{*}{$\begin{array}{l}\text { Ground } \\
\text { measured } \\
\text { (Vwt) }\end{array}$} & \\
\hline & & $\begin{array}{l}\text { Correlation } \\
\text { coefficient }\end{array}$ & $\begin{array}{l}\text { Level of } \\
\text { significance }\end{array}$ & & & & \\
\hline \multirow{2}{*}{1} & obverse & 0.843 & $<0.0001$ & 33.538 & 465 & 437 & 6.6 \\
\hline & verso & 0.767 & 20.001 & 30.786 & 338 & 375 & -100 \\
\hline \multirow{2}{*}{2} & obverse & 0.858 & 40.0001 & 32545 & 384 & 390 & -1.5 \\
\hline & verso & 0.785 & 40.0001 & 31.256 & 408 & 422 & -3.3 \\
\hline \multirow{2}{*}{3} & obverse & 0.773 & $<0.001$ & 32,529 & 377 & 377 & 0.0 \\
\hline & verso & 0.866 & $<0.0001$ & 31.217 & 414 & 435 & -4.8 \\
\hline \multirow{2}{*}{4} & obverse & 0804 & $<0,0001$ & 29054 & 362 & 437 & -17.1 \\
\hline & verso & 0.857 & $<0.0001$ & 34.864 & 432 & 375 & 15.2 \\
\hline \multirow{2}{*}{5} & obverse & 0.790 & $<00001$ & 30.385 & 354 & 399 & -11.4 \\
\hline & verso & 0.853 & $<0.0001$ & 33.913 & 448 & 413 & 8.5 \\
\hline \multirow{2}{*}{6} & obverse & 0.872 & $<0.0001$ & 31.517 & 374 & 405 & -7.6 \\
\hline & verso & 0.746 & 80.001 & 32.432 & 421 & 407 & 3.5 \\
\hline \multirow{2}{*}{7} & obverse & 0.838 & 00.0001 & 32.039 & 379 & 393 & -3.6 \\
\hline & verso & 0.781 & 0.001 & 31.799 & 414 & 419 & -1.1 \\
\hline \multirow{2}{*}{8} & obverse & 0.865 & $<0.0001$ & 33.356 & 372 & 347 & 7.0 \\
\hline & verso & 0.730 & $<0.001$ & 29.876 & 410 & 465 & -11.8 \\
\hline \multirow{2}{*}{9} & obverse & 0.754 & $<0.001$ & 30.459 & 428 & 458 & -6.5 \\
\hline & nerso & 0.849 & $<00001$ & 32.849 & 355 & 354 & 02 \\
\hline \multirow{6}{*}{10} & obverse & 0.763 & $<0.001$ & 30955 & 396 & 428 & -7.5 \\
\hline & verso & 0.866 & $<0.0001$ & 32.817 & 396 & 384 & 3.2 \\
\hline & & & Mean & 31.909 & 396 & 406 & \\
\hline & & & S.D. & 1.46 & 33 & 32 & \\
\hline & & & C.V. & 4.56 & 8.4 & 7.9 & \\
\hline & & & SE. & 0.35 & 8.1 & 78 & \\
\hline
\end{tabular}

the 20 correlation coefficients between the standing timber stock $V$ and the vegetation profile area $S$ calculated using 20 sets of randomly chosen halves of 17 plots were no less than 0.73 and highly significant with the level of significance no greater than $0.1 \%$. Small standard deviation also indicates that the correlation is consistent and stable with data from as few as 17 sample plots.

The mean of 20 regression coefficients calculated using data from 20 estimation halves turned out to be 31.9 (dimensionless) with the standard error of only 0.35 (dimensionless), indicating the robustness of the regression coefficient. The difference between the observed mean standing timber stock of 17 sample plots and their estimated counterparts ranged from -75 to $57 \mathrm{~m}^{3} / \mathrm{ha}$, or $-17.1 \%$ to $15.2 \%$ in terms of relative error with an overall mean and standard error of $396 \pm 8.1 \mathrm{~m}^{3} /$ ha in the estimated timber stock against $406 \pm$ $7.8 \mathrm{~m}^{3} /$ ha in the observed timber stock.

On the basis of the significant correlation and robust regression indicated above, the regression coefficient of $a=31.9$ based on all the 34 sample plots was judged as valid for estimating the prefecture-wide timber stock.
Land-area Estimation and Comparison with Government Figures

The laser estimates of land area and standing timber stock by municipality are shown in Table 2 . The total area of mainland Ehime differed from the GSI figure by only $0.38 \%$, indicating that our rough laser estimate by rectangular area of transect length and width of $4 \mathrm{~km}$ should be good enough for the prefecture level area estimation. When it comes to the comparison by municipality, however, the discrepancy became much more conspicuous with estimation errors over $10 \%$ for six of 19 municipalities. The largest error was found for Ikata, where one flight line (line 0 between lines -1 and 1 in Fig. 1) had to be omitted due to flight restrictions in a $5-\mathrm{km}$ bound of a nuclear power station. For more precise estimates at the municipality level, the flight lines have to be significantly closer. 
Table 2 Comparison between government statistics and airborne laser estimates in land area and standing timber stock

\begin{tabular}{|c|c|c|c|c|c|c|}
\hline & \multicolumn{3}{|c|}{ Land Area } & \multicolumn{3}{|c|}{ Standing Timber Stock } \\
\hline & \multirow{2}{*}{$\begin{array}{l}\text { Geographical } \\
\text { Survey Inst. } \\
\left(\mathrm{km}^{2}\right)\end{array}$} & \multicolumn{2}{|c|}{ Laser } & \multirow{2}{*}{$\begin{array}{c}\text { Goverument } \\
\left(\text { million } \mathrm{m}^{3}\right)\end{array}$} & \multicolumn{2}{|c|}{ Laser } \\
\hline & & $\left(\mathrm{km}^{2}\right)$ & $\frac{\text { Laser-GSI }}{\text { GSI }}$ & & $\left(\right.$ million $\left.\mathrm{m}^{3}\right)$ & / Gov. \\
\hline Ehime & 5,455 & 5,435 & $-0.38 \%$ & 87.32 & 175.53 & 2.010 \\
\hline Shikokuchuo & 420 & 362 & $-14 \%$ & 8.62 & 12.89 & 1.50 \\
\hline Niihama & 234 & 285 & $+22 \%$ & 3.95 & 8.57 & 2.17 \\
\hline Saî̀o & 509 & 511 & $\pm 0 \%$ & 8.68 & 15.14 & 1.74 \\
\hline Imabari & 286 & 281 & $-2 \%$ & 2.60 & 6.67 & 2.56 \\
\hline Matsuyama & 386 & 354 & $-8 \%$ & 3.74 & 8.26 & 2.21 \\
\hline Iyo & 194 & 214 & $+10 \%$ & 1.28 & 5.60 & 4.37 \\
\hline Toon & 211 & 215 & $+2 \%$ & 3.98 & 6.93 & 1.74 \\
\hline Masaki & 20 & 16 & $-19 \%$ & 0 & 0.07 & $\infty$ \\
\hline Tobe & 102 & 106 & $+4 \%$ & 1.50 & 3.80 & 2.54 \\
\hline$\overline{\text { Ozu }}$ & 432 & 430 & $-1 \%$ & 6.53 & 14.49 & 2.22 \\
\hline Uchiko & 300 & 299 & $\pm 0 \%$ & 4.98 & 10.73 & 2.15 \\
\hline Yawatahama & 130 & 128 & $-2 \%$ & 1.52 & 3.29 & 2.16 \\
\hline Inata & 94 & 55 & $-42 \%$ & 0.63 & 1.15 & 1.81 \\
\hline Seiyo & 515 & 523 & $+2 \%$ & 9.25 & 18.05 & 1.95 \\
\hline Kumakogen & 584 & 611 & $+5 \%$ & 13.94 & 26.73 & 1.92 \\
\hline Uwajima & 459 & 455 & $-1 \%$ & 6.44 & 13.31 & 2.07 \\
\hline Kihoku & 242 & 235 & $-3 \%$ & 4.79 & 9.16 & 1.91 \\
\hline Matsuno & 99 & 113 & $+15 \%$ & 1.75 & 4.27 & 2.44 \\
\hline Ainan & 238 & 242 & $+2 \%$ & 3.13 & 6.41 & 2.05 \\
\hline
\end{tabular}

Timber Stock Estimation and Comparison with Government Figures

Our timber stock estimates differed unequivocally from the government counterparts, even at the prefectural level. At 176 million $\mathrm{m}^{3}$, our estimate turned out to be twice as much as the government figure (OCHI et al., 2006; SHIKOKU REGIONAL Forest OfFICE, 2006; 2005; 2004; 2003; 2002) of 87 million $\mathrm{m}^{3}$. Both estimates seem responsible for this disagreement but the government figure seems much less representative of the reality than the laser estimate for the following reasons. First of all, the government statistics has long been notorious for excessive under-estimation (Fujimoto et al., 2007; MAтsumoto, 2003; SHIRAISHI, 1999) as has already been mentioned. Secondly, in our two-way comparison of the government statistics and airborne laser estimate against actual timber cruising results for a 200 ha tract in the Tomakomai National Forest in northern Japan, the former under-estimated the reality by a factor of 0.56 , whereas the latter over-estimated only by a factor of 1.09 (SwEDA and TsuzukI, 2006). Thirdly, in the "National Forest Resource Monitoring Survey" now in progress to improve the government inventory in preparation for the Kyoto Protocol forest carbon accounting, significant under-estimation is becoming evident by the very hand of the Forestry Agency responsible for the FIB (YoshiDA, personal communication). Taking all these factors into account and considering possible over-estimation on the side of laser estimate as will be discussed below, 70 to $80 \%$ of the discrepancy could be attributed to the government statistics with remaining 20 to $30 \%$ to the laser estimate. This leaves the most likely actual timber stock of the prefecture at around 155 million $\mathrm{m}^{3}$ though a series of rigorous and extensive ground truthing surveys are inevitable for a more decisive conclusion.

As was the case with the area estimate, the discrepancy was more pronounced in the comparison at the municipality level. The inconsistency tended to be relatively small in the large municipalities with high standing timber stock, and more outstanding in small municipalities like Masaki, Iyo and Tobe, all adjacent to the prefectural capital Matsuyama with little standing timber stock.

Possibility of Over-estimation in Laser Estimate

As has been mentioned above, our laser-based prefecturewide timber stock could well be over-estimating the unknown reality for four reasons. The most obvious and significant of all is counting abandoned and wooded farmland (Fig. 3) as forest. Forests have been reclaiming a considerable area of farmland over the past 40 years, as the nation's agriculture sector dwindled and the population shifted to the secondary and tertiary industries in and around cities. A considerable part of these abandoned farmlands is still registered as such, but is accounted as forest in our estimate due to their appearance. Judging from the $10 \%$ disagreement in forested area between

\section{J. For. Plann. 13:259-266(2008)}




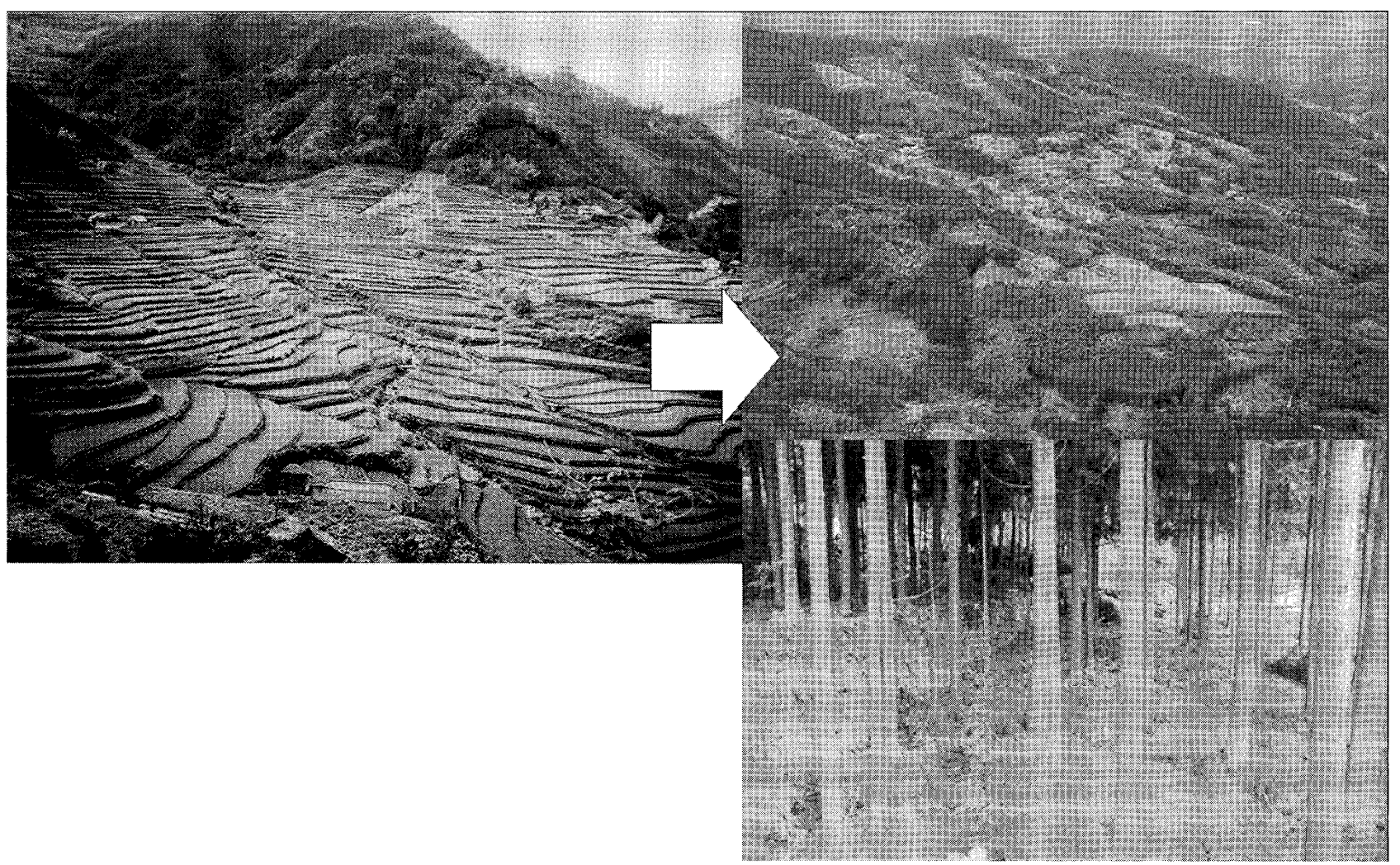

Fig. 3 Change from cropland to forest

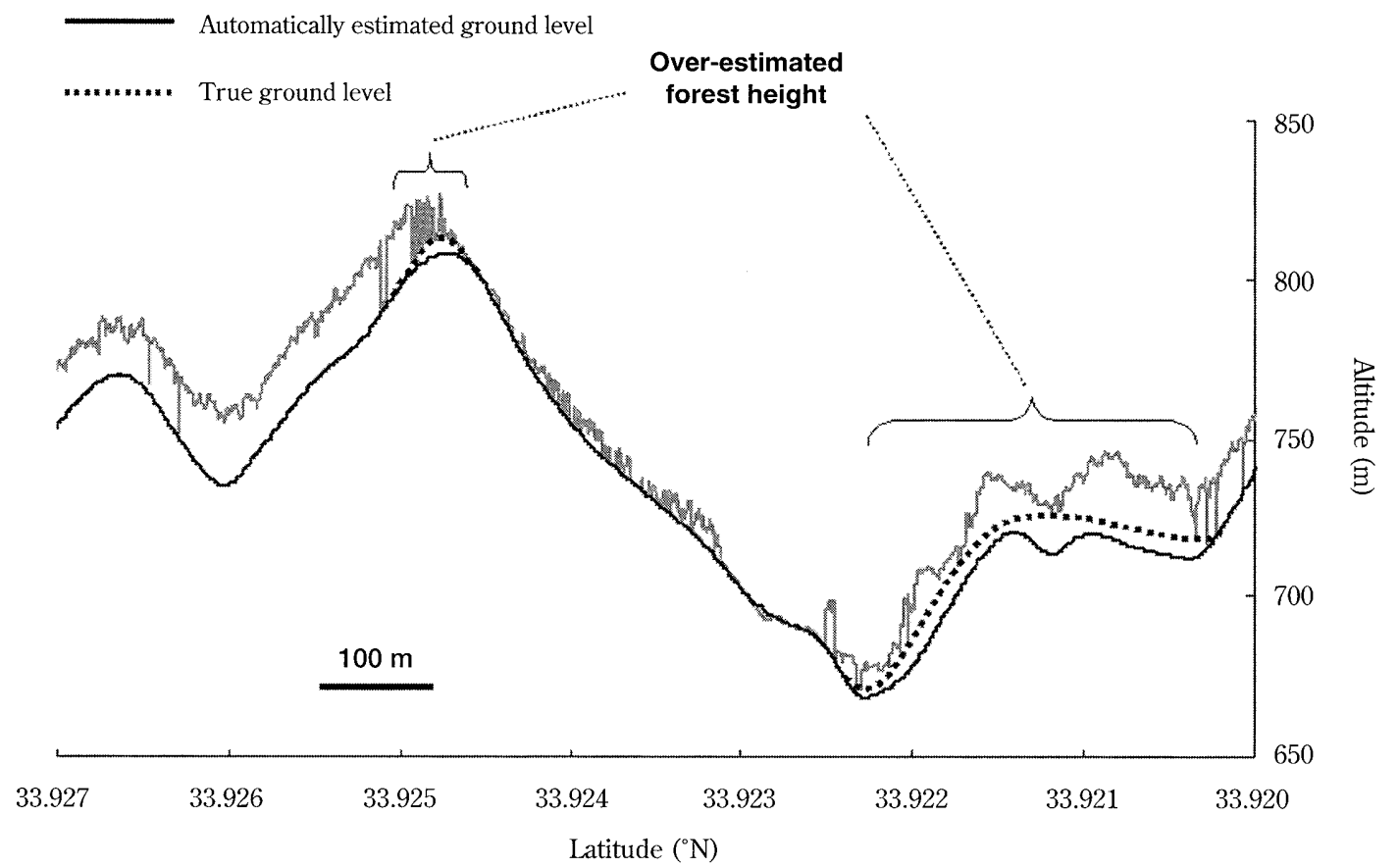

Fig. 4 Over-estimation of stand height due to poor ground level estimation 
our laser estimate and the Ministry-of-Land statistics (MAEDA et al., 2006), the reclaimed farmland could be as much as $10 \%$ of the prefecture. By simple proportional discounting, this accounts for $10 \%$ over-estimation in our figure of standing timber stock.

The second source of over-estimation could be attributed to local over-estimation of canopy height. This occurred partly from scarcity of ground returns in dense forests where thick foliage prevented the laser beam to penetrate down to the ground, and partly from the rigidity of spline curve used for estimating continuous ground level. The latter tends to shortcut missing ground returns to result in taller vegetation height than actually is as shown in Fig. 4. The third source could be the inherent tendency of over-estimation in our method of timber stock estimation, which was also the case in our previous work in the Tomakomai national forest mentioned above. The reason for this has yet to be resolved. The last and least likely source of over-estimation could be isolated trees in parks and farmland as well as along the road. However, urban and residential area and farmland respectively cover only 4 to 5 and 10 to $12 \%$ of the prefecture respectively (MINISTRY-OF-LAND, http://lucky.tochi.mlit.go.jp/; MAEDA et al., 2006), and trees and groves sporadically scattered over the areas do not seem to affect the forested area very much.

\section{CONCLUSION}

Judging from its accuracy of land-area estimation, airborne laser altimetry can give reasonably accurate estimates of standing timber stock for an area as large as a prefecture, and therefore could well be applicable to the national forest carbon accounting for the Kyoto Protocol or for the post-Kyoto, as a transparent, consistent and accurate method. However, the present density of profiling transects, i.e. $4 \mathrm{~km}$ apart from each other or $249 \mathrm{~m} / \mathrm{km}^{2}$ or altimetry point density of 2,930 points $/ \mathrm{km}^{2}$ is not sufficient for reasonable estimates at the municipality level. However the cost of increasing the transect density is minimal in comparison with the time and cost of maintaining the present system of national forest inventory.

\section{LITERATURE CITED}

Fujimoto, K., HuKadA, H., MiYama, H. and Imanishi, T., (2007): Long- term monitoring of Shimanto forest planning region. Trans. J. For Soc. E11 (in Japanese)

Maeda, Y., Tsuzuki, H., Nelson, R. and Sweda, T., (2006): Land use classification of Ehime prefecture, Japan using airborne laser altimetry. Proc. Int'l Conf. Silvilaser 2006, Matsuyama. 24-29

Matsumoto, M., (2003): What information about forest is demanded by Kyoto protocol / Marrakech agreement? Trans. Soc. J. For. Plan. Res. 407: 15-24 (in Japanese)

Ministry-Of-LAND, (2006): LUCKY (Land use control back-up system). http://lucky.tochi.mlit.go.jp/

Nelson, R., Parker, G. and Hom, M., (2003): A portable airborne laser system for forest inventory. Phot. Eng. Rem. Sen. 69: 267-273

Ochi, M., Itoh, M., Shinohara, T., Yabuki, Y., Watanabe, A., SaKamoto, Y., Kanagaki, M., Ohnishi, Y., Nishimura, T. and Jinno, T., (2006): Regional forest planning of Imabari and Matsuyama region. Ehime Prefecture, Matsuyama, vii+234pp (in Japanese)

Shikoku Regional Forest Office, (2002): National-forest planning of Nanyo region. Shikoku Regional Forest Office, Kochi, iii+28pp (in Japanese)

ShiKoKU Regional Forest OfFICE, (2003): National-forest planning of Hijikawa region. Shikoku Regional Forest Office, Kochi, iii+14pp (in Japanese)

Shikoku Regional Forest Office, (2004): National-forest planning of Chuyo Sangaku region. Shikoku Regional Forest Office, Kochi, iii+23pp (in Japanese)

Shikoku Regional Forest Office, (2005): National-forest planning of Toyo region. Shikoku Regional Forest Office, Kochi, iii $+21 p p$ (in Japanese)

Shikoku Regional Forest OfFice, (2006): National-forest planning of Imabari and Matsuyama region. Shikoku Regional Forest Office, Kochi, iii+25pp (in Japanese)

Shiraishi, N., (1999): States and problems of Japanese forest monitoring system. Bull. J. For. Soc. 27: 35-37 (in Japanese)

SwEDA, T. and Tsuzuki, H., (2006): Forest carbon budget accounting and early detection of warming-induced vegetation change using laser altimetry. Proc. 28th Symposium on Remote Sensing for Environmental Sciences. 1-12

TSUzUKI, H., (2004): Long-range estimation of standing timber stock and forest biomass using airborne laser altimetry. Ph. D Thesis. $\mathrm{v}+120 \mathrm{pp}$ (in Japanese)

Tsuzukn, H., Kusakabe, T. and SwedA, T., (2006): Long-range estimation of standing timber stock in western boreal forest of Canada using airborne laser altimetry. J. Jpn. For. Soc. 88: 103-113 (in Japanese)
(Received 17 January 2007) (Accepted 28 September 2007) 